\title{
Is a community state reachable, and why?
}

\author{
Mathieu de Goër de Herve ${ }^{1}$, Colin Thomas ${ }^{2}$, Maximilien Cosme ${ }^{1}$, Philip Warren ${ }^{3}$, and \\ Cédric Gaucherel ${ }^{1}$ \\ ${ }^{1}$ Botanique et Modélisation de l'Architecture des Plantes et des Végétations \\ ${ }^{2}$ IBISC \\ ${ }^{3}$ The University of Sheffield
}

January 24, 2022

\begin{abstract}
Deterministic models have difficulties to take into account stochasticity during community assembly. As a tool to circumvent this problem, we present a qualitative discrete-event model, where consequences of interspecific interactions are described as rules. This model provides a map of all possible future dynamics for a given system, which allows to exhaustively describe the possible pathways during an assembly process. Such a description does not rely on species traits details and is insensitive to stochastic effects. This allows to show that subsets of species are sometimes impossible to reach starting from larger sets of species, and therefore to question the reachability of community states during the system's dynamics. Applying the model to an experimental dataset studying the collapse of protist communities, we obtain a very good theory-experiment agreement. We finally discuss what the notion of reachability can bring to community assembly.
\end{abstract}

\section{Hosted file}

degoer2022.pdf available at https://authorea.com/users/456952/articles/553859-is-acommunity-state-reachable-and-why 